Article

\title{
Next-Generation Sequencing on Insectivorous Bat Guano: An Accurate Tool to Identify Arthropod Viruses of Potential Agricultural Concern
}

\author{
Mathieu Bourgarel ${ }^{1,2}$, Valérie Noël ${ }^{3}$, Davies Pfukenyi ${ }^{4}$, Johan Michaux ${ }^{1,5}$, Adrien André ${ }^{5}$ (D), \\ Pierre Becquart $^{3}$, Frédérique Cerqueira ${ }^{6}$, Célia Barrachina ${ }^{7}$, Vanina Boué ${ }^{3}$, Loïc Talignani ${ }^{3}$, \\ Gift Matope ${ }^{4}$, Dorothée Missé ${ }^{3} \mathbb{D}$, Serge Morand ${ }^{1,8}(\mathbb{D})$ and Florian Liégeois ${ }^{3, *(D)}$
}

1 Animal Santé Territoire Risque Environnement- Unité Mixe de Recherche 117 (ASTRE) Univ. Montpellier, Centre International de Recherche Agronomique pour le Développement (CIRAD), Institut National de la Recherche Agronomique, 34398 Montpellier, France; mathieu.bourgarel@cirad.fr (M.B.); serge.morand@cirad.fr (S.M.)

2 Centre International de Recherche Agronomique pour le Développement (CIRAD), Research Platform-Production and Conservation in Partership, Unité Mixe de Recherche ASTRE, Harare, Zimbabwe

3 Maladies Infectieuses et Vecteurs: Ecologie, Génétique, Evolution et Contrôle- Unité Mixe de Recherche 224 (MIVEGEC), Institut de Recherche pour le Développement (IRD), Centre National de Recherche Scientifique (CNRS), Univ. Montpellier, 34398 Montpellier, France; valerie.noel@ird.fr (V.N.); pierre.becquart@ird.Fr (P.B.); svetnina@yahoo.fr (V.B.); loic.talignani@ird.fr (L.T.); dorothee.misse@ird.fr (D.M.)

4 Faculty of Veterinary Science, University of Zimbabwe, P.O. Box MP167, Mt. Pleasant Harare P.O. Box MP167, Zimbabwe; dpfukas@gmail.com (D.P.); gmatope@vet.uz.ac.zw (G.M.)

5 Université de Liège, Laboratoire de Génétique de la Conservation, GeCoLAB, 4000 Liège, Belgium; johan.michaux@ulg.ac.be (J.M.); adrien.andre@uliege.be (A.A.)

6 Institut des Sciences de l'Evolution de Montpellier (ISEM), Univ Montpellier, Centre National de Recherche Scientifique (CNRS), Ecole Pratique des Hautes Etude (EPHE)s, Institut de Recherche pour le Développement (IRD), 34398 Montpellier, France; frederique.cerqueira@umontpellier.fr

7 Montpellier GenomiX (MGX), Biocampus Montpellier, Centre National de Recherche Scientifique (CNRS), Intitut National de la Santé et de la Recherche Médicale (INSERM), Univ Montpellier, 34094 Montpellier, France; celia.barrachina@mgx.cnrs.fr

8 Institut des Sciences de l'Evolution de Montpellier (ISEM) Univ. Montpellier, Centre National de Recherche Scientifique (CNRS), Institut de Recherche pour le Développement (IRD), Centre International de Recherche Agronomique pour le Développement (CIRAD), 34000 Montpellier, France

* Correspondence: florian.liegeois@ird.fr

Received: 12 October 2019; Accepted: 26 November 2019; Published: 28 November 2019

\begin{abstract}
Viruses belonging to the Dicistroviridae family have attracted a great deal of attention from scientists owing to their negative impact on agricultural economics, as well as their recent identification as potential aetiological agents of febrile illness in human patients. On the other hand, some Dicistroviruses are also studied for their potential biopesticide properties. To date, Dicistrovirus characterized in African mainland remain scarce. By using High-Throughput Sequencing technology on insectivorous bat faeces (Hipposideros Caffer) sampled in a cave used by humans to collect bat guano (bat manure) as fertilizer in Zimbabwe, we characterized the full-length sequences of three Dicistrovirus belonging to the Cripavirus and Aparavirus genus: Big Sioux River Virus-Like (BSRV-Like), Acute Bee Paralysis Virus (ABPV), and Aphid Lethal Paralysis Virus (ALPV). Phylogenetic analyses of ORF-1 and ORF-2 genes showed a complex evolutionary history between BSRV and close viruses, as well as for the Aparavirus genus. Herewith, we provide the first evidence of the presence of Dicistrovirus in Zimbabwe and highlight the need to further document the impact of such viruses on crops, as well as in beekeeping activities in Zimbabwe which represent a crucial source of income for Zimbabwean people.
\end{abstract}


Keywords: Dicistrovirus; Bats; Faeces; Phylogeny; HTS; Zimbabwe

\section{Introduction}

Dicistroviridae is a family of non-enveloped viruses with a linear ssRNA genome of approximately 7-10 kb. The Dicistrovirus RNA genome contains two non-overlapping open reading frames (ORFs) separated by an Inter-Genic Region (IGR) internal ribosome entry site (IRES) [1]. In the absence of 5 'cap, Dicistroviral RNA is translated by means of an IRES. The ORF-1 encodes for the non-structural proteins, whereas the ORF-2 encodes for structural proteins. Replication occurs in the cytoplasm of an infected cell. According to the International Committee on Taxonomy of Viruses (ICTV), the Discistrovirus comprises three different genera: the Triatovirus, Aparavirus, and Cripavirus [2].

All classified Dicistrovirus members infect arthropod hosts, and some of them can wreak havoc in beehives (e.g., the Acute bee paralysis virus and Israeli acute paralysis virus, which infect domesticated bees) or in shrimp and crab farming (e.g., the Taura syndrome virus, Macrobrachium rosenbergii virus, Mud crab dicistrovirus) and might have a devastating economic impact [3-8]. Besides, some dicistroviruses are pathogenic to insect pests of agricultural or medical importance, rendering them as potentially interesting biopesticides [3]. Dicistroviruses are likely to be ubiquitous and have been identified in multiple environments $[9,10]$.

The transmission of the Dicistrovirus can occur in different ways: horizontally, per os, via viral particles present in the faeces of infected arthropods from females to males [11] or via plant-mediated transmission [12], and vertically, by transovarian or transovum transmission [13-15]. Additionally, the Dicistrovirus can also be transmitted through vectors such as Varroa's mite [16].

Beyond the classified Dicistrovirus species, numerous dicistroviruses which are yet to be classified have been characterized in the last two decades mainly owing to the advent of high-throughput sequencing technologies (HTS). Although numbers of them were identified in insects [12,17-22], some were found in mammalian stools, including human beings. However, the presence of such viruses in mammalian faeces were likely linked to their dietary habits [23-28].

Recently, blood-associated Dicistroviruses were described in both bats and humans [29-31]. Notably, in Tanzania, Dicistrovirus genome sequences were detected in 103 out of 670 (15.3\%) sera tested from febrile Tanzanian children. More interestingly, these results were confirmed by real-time RT-PCR in 30 out of the 38 sera tested with a median of $5.7 \times 10^{3}\left(1.32 \times 10^{3}-1.44 \times 10^{7}\right)$ viral RNA copies/mL of sera [30]. Although this study did not allow to establish a clear link between this viral infection and the febrile state of children, it highlighted the need to further document the potential spillover of these viruses from their arthropod hosts to mammals, and particularly in human beings. However, in order to assess the human's viral exposure risk, it is crucial to characterize circulating viruses in human working environments, especially where interface with wildlife is involved.

In this study, by using HTS technologies on a pool of insectivore bat faeces collected in a cave known to be regularly used by humans, we provide the first evidence of the Big Sioux River Virus-like (BSRV-like), Aphid Lethal Paralysis Virus (ALPV), and Acute Bee Paralysis Virus (ABPV) circulation in Zimbabwe.

\section{Materials and Methods}

\subsection{Collection of Samples}

Between June 2016 and February 2017, insectivorous bat (Hipposideros caffer) faecal samples were collected in the Magweto cave (S17.10024 $4^{\circ}$ E029.19214 ${ }^{\circ}$ ), which is regularly visited by local communities to collect bat guano, which they use as fertilizer [31]. Two square meters of plastic sheets were laid down in the cave underneath the bat colonies overnight (five plastic sheets per cave). Faeces were collected from each plastic sheet at a rate of $\approx 6 \mathrm{~g}$ of pooled faeces in a $15 \mathrm{~mL}$ tube containing 
$6 \mathrm{~mL}$ of home-made RNA stabilization solution which allowed for avoidance of RNA degradation during the field mission [32]. Samples were stored at $-80^{\circ} \mathrm{C}$ until laboratory analyses.

\subsection{Species Identification}

Bat species were identified by Cytochrome $b$ amplification [33] and sequencing after DNA extraction using the Qiamp DNA stool (Qiagen S.A, Courtaboeuf, France). Cytochrome b sequences were then compared to the bat sequences available in the GenBank database using the Basic Local Alignment Search Tool (BLAST) program, and species were confirmed by phylogenetic analysis (Figure S1). Only bats from Hipposideros spp. were identified. Following the current literature, only two different Hipposideros bat species have been reported in Zimbabwe to date: Hipposideros caffer and Hipposideros vittatus [34]. All our samples were closer to H. caffer than any other Hipposideros species [32].

\subsection{Diet Identification}

DNA was extracted from each sample with the QIAamp DNA Stool Mini Kit (Qiagen, Hombrechtikon, Switzerland). PCR amplification was duplicated for each sample on a portion of the mitochondrial cytochrome oxydase I gene [35]. Negative DNA extraction and negative PCR controls were included in the procedure. Agencourt AMPure XP beads (BeckmanCoulter Life Sciences, Indianapolis, IN, USA) and then the Quant-iTTMPicoGreen ${ }^{\circledR}$ dsDNA Assay Kit (Thermo Scientific, Waltham, MA, USA) were used to purify PCR products and to quantify purified amplicons, respectively. After the quantification step, products were pooled at equimolarity and sent to the GIGA Genomics platform (University of Liège, Belgium) for sequencing on an ILLUMINA NextSeq benchtop sequencer. Raw sequences were analyzed as described previously [36].

\subsection{RNA Extraction}

RNA extraction was carried out from a pool of faecal samples collected on the same plastic sheet. Four sample tubes from the same plastic sheet were pooled and transferred to a $50 \mathrm{~mL}$ tube with $10 \mathrm{~mL}$ of PBS 1X, then was vigorously mixed and centrifuged at $4500 \mathrm{rpm}$ for $10 \mathrm{~min}$ (Centrifuge Jouan GR4i). The supernatant was filtered using gauze in order to eliminate faecal matter, and transferred into fresh tubes before re-centrifuging at $4500 \mathrm{rpm}$ for $10 \mathrm{~min}$ (Centrifuge Jouan GR4i). The supernatant was filtered through a $0.45 \mu \mathrm{m}$ filter to remove eukaryotic and bacteria-sized particles. Seven milliliters of the filtered samples were centrifuged at $250,000 \mathrm{~g}$ for $2.5 \mathrm{~h}$ at $4{ }^{\circ} \mathrm{C}$. The pellets were re-suspended in $600 \mu \mathrm{l}$ molecular-grade $\mathrm{H} 20$, and $150 \mu \mathrm{l}$ was used to extract RNA using the NucleoSpin ${ }^{\circledR}$ RNA Kit (Macherey-Nagel, Hoerdt, France) according to the manufacturer's protocol. Then, RNA was DNAse-treated by using the Turbo DNA-free kit (Thermo Fisher Scientific, Illlkirch France).

\subsection{RNA Sequencing and rRNA Depletion}

The RNA-Seq library was constructed with the Truseq stranded mRNA sample preparation (low-throughput protocol) kit from Illumina. One microgram of total RNA was used for the rRNA depletion using the Ribo-Zero rRNA Removal Kit (Illumina, San Diego, CA USA). Purified mRNAs were validated by capillary electrophoresis on a Fragment Analyzer (Advanced Analytical, Ankeny, IA, USA

\subsection{Library Construction}

Approximately $7.5 \mathrm{ng}$ of purified mRNA were used for the library construction. They were fragmented into small pieces using divalent cations under elevated temperature. The cleaved RNA fragments were copied into first-strand cDNA using SuperScript II reverse transcriptase, Actinomycin $\mathrm{D}$, and random hexamer primers. The second-strand cDNA was synthesized by replacing dTTP with dUTP. These cDNA fragments then had the addition of a single " $\mathrm{A}$ " base and subsequent ligation of the 
adapter. The products were then purified and enriched with 15 cycles of PCR. The final cDNA library was validated with a Fragment Analyzer (Advanced Analytical, Ankeny, IA, USA) and quantified with a KAPA qPCR kit (Kapa Biosystems, Wilmington, MA USA).

\subsection{Library Sequencing}

The library was denatured using $\mathrm{NaOH}$ and diluted to $12 \mathrm{pM}$ with $5 \%$ of PhiX before loading on a MiSeq (Illumina, San Diego, CA USA). Cluster formation, primer hybridization, and sequencing of 300 cycles in the paired-end read were performed with a reagent kit v3 (600 cycles).

\subsection{Bioinformatic Analyses}

Illumina adapters were trimmed using MiSeq Reporter software. We obtained 8,680,414 paired reads. Quality was checked using FastQC software (bioinformatics.babraham.ac.uk/projects/fastqc/). Due to the low sequence quality per base in reads 2, only reads 1 were used. Reads were compared to the C-RVDBv12.2 viral database [37] using BLAST 2.6.0 [38] (command lines in Figure S2). Matching reads amounted to 524,042 (6.04\% of total reads). There were 160,737 reads which were identified as Big Sioux River viruses, 796 as Acute Bee Paralysis viruses, and 282 as Aphid Lethal Paralysis viruses. A total of 161,815 Dicistrovirus reads (30.88\% of viral reads) were identified. These reads were extracted (see command lines in Supplementary Materials Text S3) and analysed with Geneious software (Biomatters LTD, Auckland, NZ).

\subsection{Polymerase Chain Reactions}

The RNA extracted from the sample's pool was reverse-transcribed using random hexamers. The ALPV, ABPV, and BSRV specific primers were designed and used to amplify the targeted viruses. PCR products were then agarose-gel purified (Geneclean Turbo Kit, MP Biomedicals, Illlkirch, France) and directly sequenced in both $5^{\prime}$ and $3^{\prime}$ directions using cycle sequencing and dye terminator methodologies (Eurofins, Ebersberg, Germany). Overlapping sequences were assembled into contiguous sequences using SEQMAN DNASTAR software (Lasergene, DNASTAR, Inc., Madison, WI, USA).

\subsection{Genetic Analyses}

Predicted ORF-1 and ORF-2 Dicistrovirus amino acid sequences were aligned using MEGA 7 [39], with minor manual adjustments. Sites that could not be unambiguously aligned were excluded, and divergent regions were excluded from subsequent analyses. Phylogenies were inferred using the Maximum Likelihood (ML) method implemented in PhyML [40]. The reliability of branching orders was tested using the bootstrap approach (1000 replicates). The suited evolution model (LG + Г4 + I) was selected by Akaike's Information criterion (AIC) using Topali software [41]. Identity analyses were done using ClustalX [42].

In order to study whether the newly characterized BSRV-like virus sequence was recombinant with any of the other related viruses, similarity plot analyses using the SIMPLOT package version 2.5 (Ray, 1999; http://www.med.jhu.edu/deptmed/sray) was performed on the nucleotide alignment with the new BSRV-like virus sequence and known BSRV and BSRV-like virus strains available in the NCBI GenBank with a sliding window of 200 nucleotides (nt) moving in steps of $50 \mathrm{nt}$. We excluded a total of $190 \mathrm{nt}$ from divergent positions, mainly due to nucleotide (nt) insertion and/or deletion linked to the $R h P V$ strains from this alignment, as well as the $5^{\prime}$ and $3^{\prime}$ UTR. Overall, the removed nucleotides represented 2.1\% of the ORF1-IGR IRES-ORF2 genome with a total 52 nt removed from the ORF-1-55 from the IGR-IRES and 87 from the ORF-2, respectively. For the latter, $84 \mathrm{nt}$ were removed only from the $R h P V$ strains at the $3^{\prime}$ part of the ORF-2 due to the longer $R h P V$ sequences than the other viruses. Actually, the adjustment realized for this alignment did not impact the SIMPLOT analysis. 


\subsection{GenBank Accession Numbers}

The metagenomic data have been deposited to the Sequence Read Archive (SRA) under the accession number PRJNA574024.

The GenBank accession numbers of BSRV-like CR-026, ALPV CR-026, and ABPV CR-026 full genome sequences are MN510867, MN510868, and MN510869, respectively.

\section{Results}

\subsection{Diet Composition}

Faeces samples (CR-026; tubes 16 and 17)) were also analyzed. The sequencing and initial sequence validation yielded to a mean of 9627 and 8257 reads. These reads produced 294 and 216 distinct sequences. Sequences presenting less than five reads were discarded, and the remaining sequences were clustered into 41 and 29 MOTUs that were compared to BOLD [43]. According to the sample, the final, complete dataset represented a panel of 14 and 11 identified arthropods. They mainly correspond to lepidopters, which are consumed by the bat we studied. However, two dipters of the genera Protoclythia and Hydrotaea were also identified. These specimens could correspond to Protoclythia modesta and Hydrotaea scambus, but these identifications at the species level have to be considered with caution, as the percentage of matching with the sequences available in the public databases is not maximal $(97.5 \%$ and $98.7 \%$, respectively). This result is probably linked to the important lack of African arthropod sequences presently available in these databases.

\subsection{Sequencing Results}

The raw sequence number obtained by the HTS was 8,680,414 reads. Indeed, 161,815 reads belonged to the Dicistroviridae viral family, representing $30.8 \%$ of the viral reads obtained. The majority of the Dicistrovirus sequences generated (161,019 reads) were close to the Cripavirus genus, whereas 796 reads were close to the Aparavirus genus. By using De Novo Assemble command in Geneious Prime software, we obtained 13 contigs with a nucleotide range from 156 to 9858 bases. By using NCBI-BLAST (https://blast.ncbi.nlm.nih.gov/Blast.cgi) with default parameters (Megablast) and a "nucleotide" database, one contig (9983 nt) matched with the Big Sioux River Virus (BSRV) with a percentage of similarity of $91 \%$, five contigs of size 5458, 2478, 1498, 334, and 247 nt matched with the Aphid Lethal Paralysis Virus (ALPV) with a percentage of similarity of 95.6\%, 98\%, 97\%, 95.2\%, and $97.6 \%$ for each contig, respectively, and seven contigs of size 4289, 1903, 1745, 1082, 759, 574, and $536 \mathrm{nt}$ matched with the Acute Bee Paralysis Virus (ABPV) with a percentage of similarity of $85 \%, 82.6 \%, 84.3 \%$, $91 \%, 86 \%, 80 \%$, and $86.4 \%$ for each contig, respectively. Then, the different contigs were mapped onto the adapted GenBank reference sequences (ABPV-AF486073; ALBV-MF458893; BSRV-KY933259) using Geneious Prime software.

\subsection{Genome Recovery}

The $B S R V$-like virus genome was fully sequenced with a depth of coverage of $X 7433$ and a full complete sequence length of 9983 nucleotides. $A B P V$ was partially sequenced with a depth coverage of X 79. Three gaps of $290 \mathrm{bp}, 445 \mathrm{bp}$, and $310 \mathrm{bp}$, respectively, were recovered by using specific primers. The $A L P V$ was also partially recovered with a depth of coverage of $\mathrm{X} 17$ and a gap of $70 \mathrm{bp}$. For $A B P V$ and $A P L V$, the gaps were filled using Reverse transcription with random hexamer primers, followed by a nested PCR using specific primers. The presence of the BSRV-like virus was also confirmed by Reverse transcription with random hexamer primers, followed by a nested PCR using specific primers on the RNA extracted from the faecal pool sample. The specific primers used are shown in the Supplementary Materials, Text S4. All amplicons were then purified and sequenced using the Sanger method. Finally, we generated three full genomes with a length of $9983 \mathrm{nt}$ for $B S R V, 9744 \mathrm{nt}$ for $A L P V$, and $9525 \mathrm{nt}$ for $A B P V$, respectively. 
The three viruses-the BSRV-like virus, $A L P V$, and $A B P V$-showed all the genetic features previously described for the Dicistroviridae family, including two ORF separated by an IGE-IRES for which the nucleic acid's length was consistent with that described for such viruses (BSRV-like virus = $597 \mathrm{nt}, A L P V=199 \mathrm{nt}$, and $A B P V=184 \mathrm{nt})$.

\subsection{Phylogenetic Analyses}

To compare the three new Dicistroviruses obtained in this study to previously characterized Dicistroviruses, we performed phylogenetic tree analyses on both ORF-1 and ORF-2 amino acid sequences. For the ORF-1 we generated two different alignments. The first one included the Solenopsis invicta virus-1 (SINV-1), which belongs to the Aparavirus genus, and the second without this virus. The first $5^{\prime}$ part of SINV-1 is considerably shorter than the other dicistroviruses. Thus, the non-use of $S I N V-1$ in the alignment allowed us to recover more than $300 \mathrm{AA}$ representing $>30 \%$ of supplementary genetic information within the ORF-1 (Figure 1a,b). Indeed, the tree topologies differed between these two alignments. The phylogenetic tree, including SINV-1, presented a cluster with two clades defined as Aparavirus-1 and Aparavirus-2 [44], whereas without SINV-1, this cluster split into two different clusters, suggesting a more complex evolutionary history within the Aparavirus genus (Figure 1a,b) than previously described. Actually, the Aparavirus clade in the ORF-1, including SINV-1, is not well-sustained with a bootstrap value of solely 340/1000 which expresses a non-resolved phylogeny within the Aparavirus genus, whereas in the ORF-2 the Aparavirus clade is well-sustained.

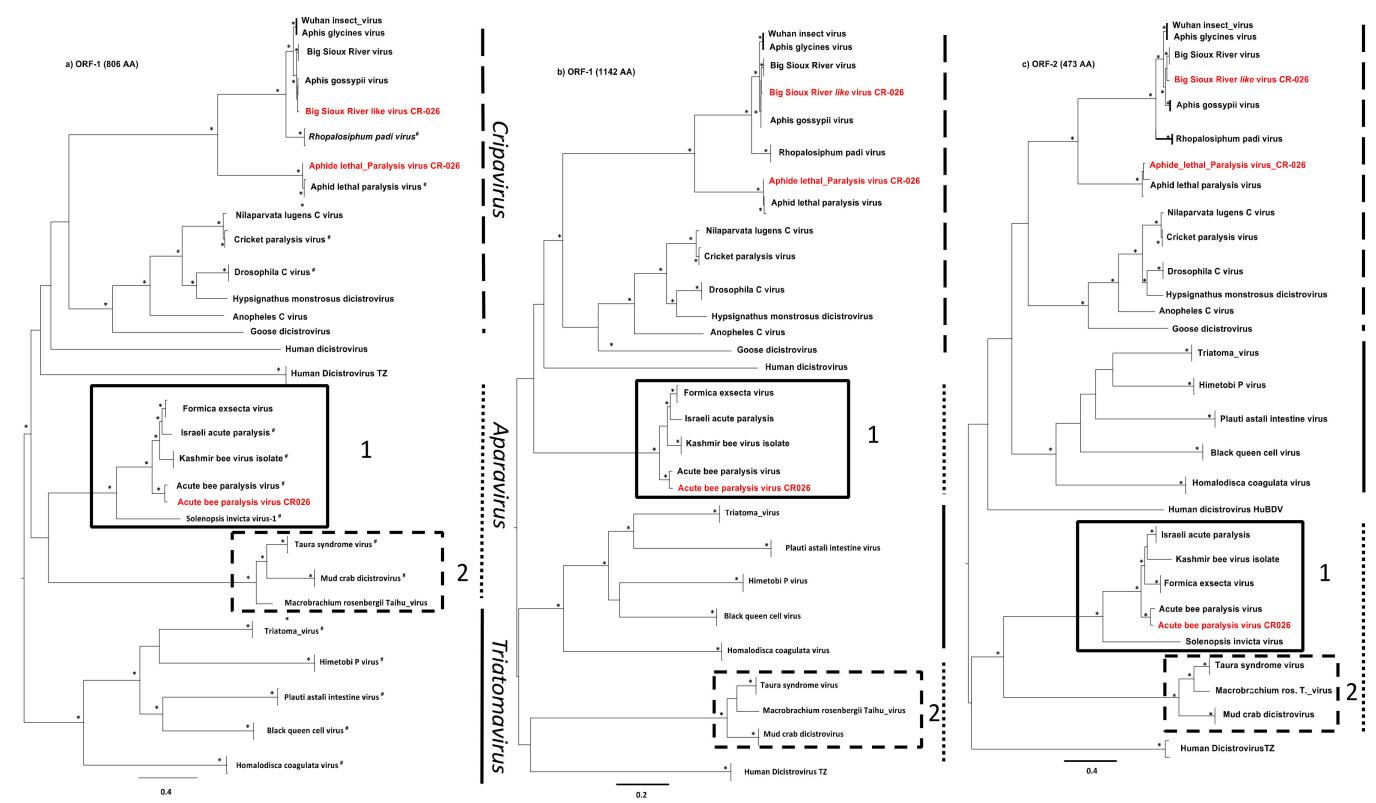

Figure 1. Phylogenetic relationships between BSRV-like CR-026, ALPV CR-026, and ABPV CR-026 with other representative Dicistroviruses. Phylogenies were inferred using Maximum Likelihood methods implemented in PhyML under the $\mathrm{LG}+\Gamma_{4}+\mathrm{I}$ model of evolution. Stars at nodes represent bootstrap $(\geq 70 \%)$ values. Scale bars indicate substitution per site. The new Dicistrovirus strains are highlighted in red. Figure 1a represents the phylogenetic topology of ORF-1, including Solenopsis invicta virus-1; Figure $1 \mathbf{b}$ represents the phylogenetic topology of ORF-1, excluding the Solenopsis invicta virus-1; Figure 1c represents the phylogenetic topology of ORF-2. Viruses in the bold rectangle belong to the Aparavirus-1 genus, whereas viruses in the dashed rectangle belong to the aparavirus-2 genus. The vertical lines represent the different Dicistrovirus genera. The \# symbol represents Dicistroviruses currently recognized by the ICTV. The Dicistrovirus reference strains used for these analyses are listed in the Supplementary Materials, Text S5.

The APLV CR-026 and ABPV CR-026 identified in this study clustered with the previously characterized $A B P V$ and $A L P V$ (Figure 1). Full-length genome genetic distance analyses showed that 
ALPV CR-026 shared 96\% of nucleotide identities with the ALPV KE P9 strain recently identified from maize leaves in Kenya [12] and with different $A L P V$ strains characterized in China (Figure 2A). Only three $A B P V$ complete genomes were available in the GenBank. $A B P V$ CR-026 presented $83 \%$ of nucleotide identity and 91 to $93 \%$ of amino acid identities with these viruses (Figure 2B), which together shared 94 to $97 \%$ of nucleotide identities.

(A)

\begin{tabular}{|c|c|c|c|}
\hline & \multicolumn{3}{|c|}{ ALPV CR-026 } \\
\hline & ORF-1 & ORF-2 & $\begin{array}{l}\text { Full length } \\
\text { Genome }\end{array}$ \\
\hline & NA AA & NA AA & NA \\
\hline MF458892.1 ALPV strain Kenya Maize & 9799 & 9397 & 96 \\
\hline MF795135.1 ALPV isolate SX China & 9799 & 9298 & 96 \\
\hline MF795134.1 ALPV isolate BJ1 China & 9799 & 9298 & 96 \\
\hline KX883690.1 ALPV strain spider133997 China & 9699 & 9298 & 96 \\
\hline KX883929.1 ALPV strain QTM16 China & 9399 & 9298 & 95 \\
\hline NC 004365.1 ALPV South Africa & & 9699 & 94 \\
\hline AF536531.1 ALPV South Africa & 9497 & 9699 & 94 \\
\hline KX830963.1 ALPV isolate TM19 East Timor & 9097 & 9297 & 94 \\
\hline MF458893.1 ALPV Kenya & & 8693 & 90 \\
\hline LN907588.1 ALPV isolate KE-P7 & & 8693 & 89 \\
\hline LN907586.1 ALPV isolate KE-P9 & 9095 & 8693 & 89 \\
\hline JX480861.1 ALPV Israel & 9095 & 8594 & 89 \\
\hline JQ320375.1 ALPV China & 9096 & 8694 & 89 \\
\hline KX884276.1 ALPV strain WHCCII13327 China & 8995 & 8494 & 88 \\
\hline KX610809.1 ALPV isolate MI USA & 8893 & & 87 \\
\hline JX045858.1 ALP isolate 4782 Spanish & 8087 & 8291 & 82 \\
\hline KJ817182.1 ALPV isolate AP USA & $80 \quad 87$ & 8291 & 81 \\
\hline
\end{tabular}

(B)

\begin{tabular}{|c|c|c|c|}
\hline & \multicolumn{3}{|c|}{ ABPV CR-026 } \\
\hline & ORF-1 & ORF-2 & $\begin{array}{l}\text { Full length } \\
\text { Genome }\end{array}$ \\
\hline & NA AA & NA AA & NA \\
\hline NC_002548.1 ABPV UK & \begin{tabular}{|ll}
83 & 91 \\
\end{tabular} & 8291 & 83 \\
\hline AF486073.2 ABPV Poland & 8391 & 8293 & 83 \\
\hline AF486072.2 ABPV Hungary & 8391 & $83 \quad 92$ & 83 \\
\hline
\end{tabular}

(C)

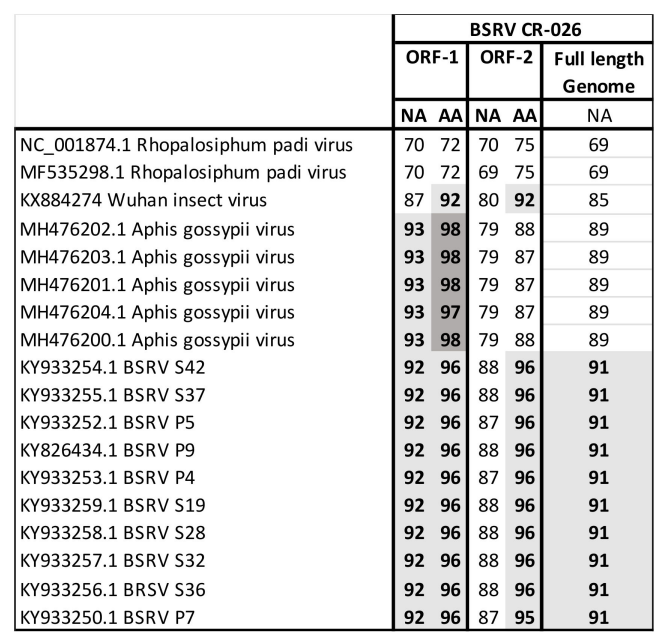

Figure 2. Nucleotide and amino acid identities between: (A) Nucleotide acid and amino acid identities between $A L P V C R-026$ and other $A L P V$ full-length genomes previously reported; (B) Nucleotide identities and amino acid between ABPV CR-026 and other ABPV full-length genomes previously reported; and (C) Nucleotide and amino acid identities between BSRV CR-026 and viruses belonging in the same phylogenetic cluster. Grey boxes highlight the NA and AA identities between BSRV CR-026 and closer viruses. 
BSRV-Like CR-026 clustered with the previously described BSRV [12], as well as with the Wuhan insect virus (WIV) [22] and Aphis glycines virus (AGLV) [18] characterized in China and Aphid gossypii virus ( $A G V$ ) isolated in Israel (Figure 1). Sequences of $A G L V$ were available in the GenBank but with no publication associated. Altogether, these viruses grouped with the Rophalosiphum padi virus (RhPV) and $A L P V$, and formed the Cripavirus genus. Amino acid and nucleotide identities showed that BSRV-Like $C R-026$ was closer to $A G V$ in the ORF-1 and to BSRV in the ORF-2 (Figure 2C). Nonetheless, the difference between $B S R V$ like $C R-026, B S R V$, and $A G V$ in the $0 R F-1$ is very weak, suggesting a common origin of these three viruses.

In order to further understand the relationship within this group of viruses, we proceeded by using ORF-1 and 2 amino acid sequences, as well as new phylogenetic analyses, including BSRV, $B S R V$-like $C R-026, A G V, W I V, A G L V$, and RhPV as the out-group. In the ORF-1, although the clade of $B S R V, B S R V$-like CR-026, AGV, WIV, and AGLV was phylogenetically well-sustained, the positioning of the different viruses in this clade remained unclear and the relationship between this group of viruses has yet to be disentangled (Figure 3a). In the ORF2, BSRV-like CR-026 clustered with the previously reported $B S R V$, and could represent a new $B S R V$ sub-type (Figure $3 b$ ).

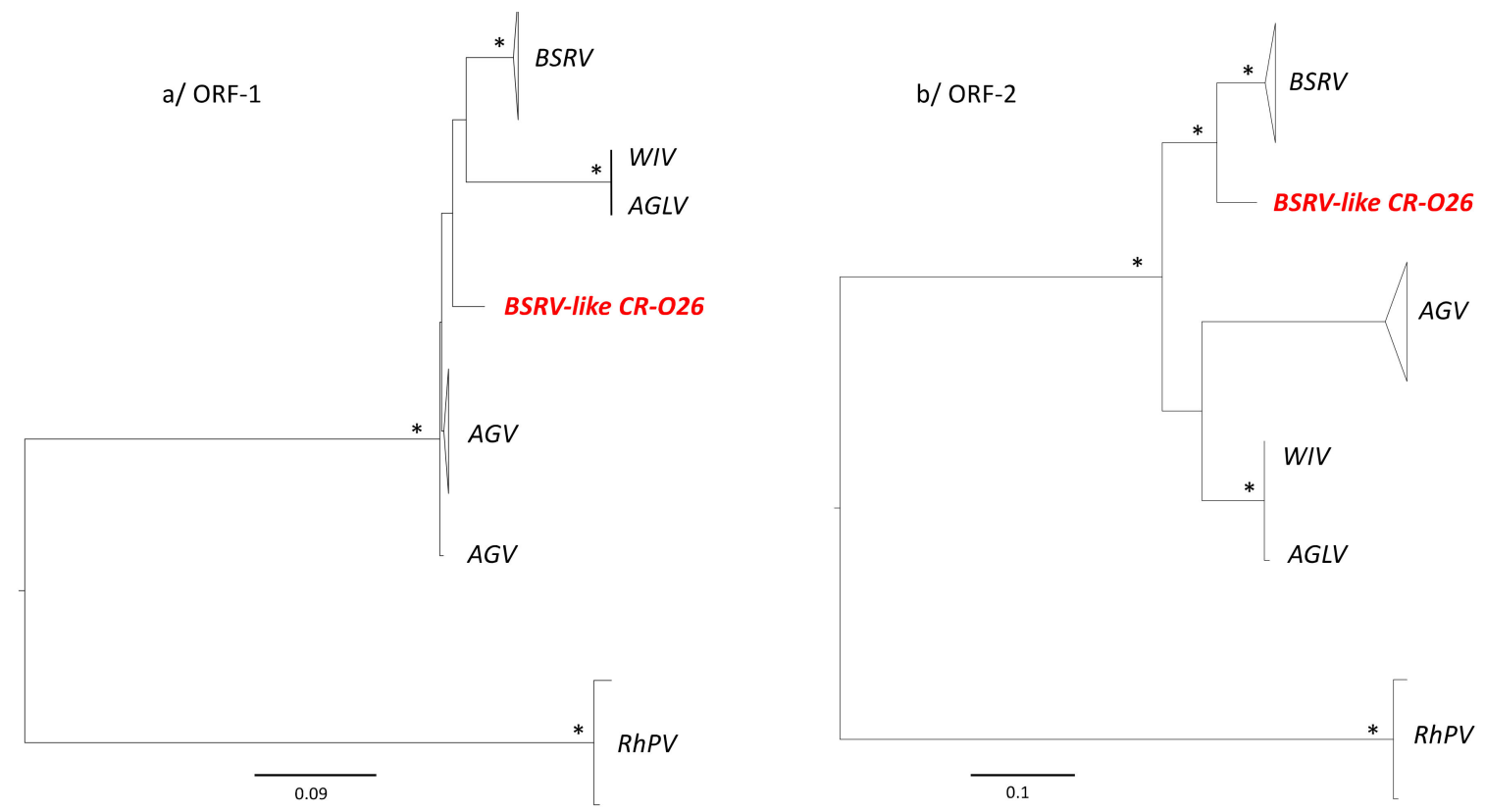

Figure 3. Phylogenetic relationships between BSRV-like CR-026 with other representative Cripaviruses close to $B S R V$ strains. Phylogenies were inferred using Maximum Likelihood methods implemented in PhyML under the LG $+\Gamma_{4}+$ I model of evolution. Stars at nodes represent bootstrap $(\geq 70 \%)$ values. Scale bars indicate substitution per site. The new BSRV-like CR-O26 strains are highlighted in red. Figure 2a represents the phylogenetic topology of ORF-1; Figure $2 \mathbf{b}$ represents the phylogenetic topology of ORF-2. RhPV was used as the out-group.

The SIMPLOT analysis confirmed our phylogenetic observations (Figure 4a). However, in the SIMPLOT analysis we observed that in the ORF-1, the new BSRV-like CR-026 strain was closer to the $A G V$ strains than other viruses in some parts of the nt sequence. In order to disentangle these complex phylogenetic relationships, we provided sequential phylogenetic analyses of the ORF-1 based on the SIMPLOT analysis (Figure $4 \mathrm{~b}$ ). This sequential analysis showed that $B S R V$-like $C R 026$ was positioned at the root of the BSRV and $A G V$ clade in the trees 1, 4, 5. In the trees 2, 3, and 7, BSRV-like CR026 were clustered with $A G V$, but the clades were not well-sustained, except for tree 3 . In tree 4, the position of the BSRV-like CR026 was also unresolved (Figure $4 \mathbf{b}$ ). 

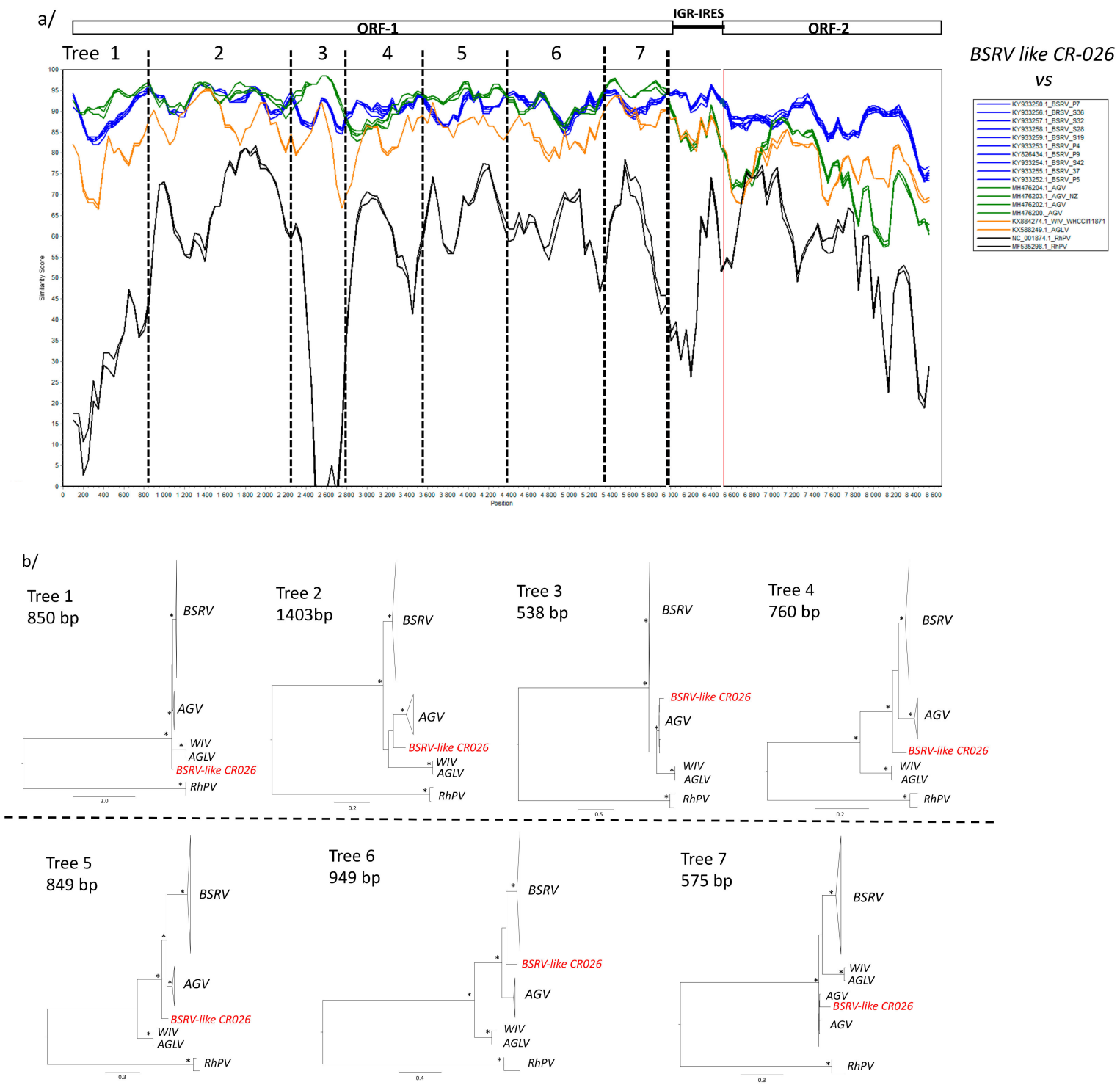

Figure 4. SIMPLOT analyses of the new BSRV-like CR-026 whole genome sequences versus other Cripavirus lineages. (a) SIMPLOT analyses were performed using the full-length nucleic acid alignment of the Cripavirus of interest with the SIMPLOT package version 2.5 with a sliding window of 200 nucleotides (nt) moving in steps of $50 \mathrm{nt}$. Blue lines represent BSRV strains, orange lines represent WIV strains, green lines represent AGV strains, and black lines represent $R h P V$ strains. Vertical black dash lines represent the partitions used for further phylogenetic analyses. (b) Phylogenetic analysis of partitioned ORF-1 nucleotide acid sequence based on the SIMPLOT analysis. Phylogenies were inferred using Maximum Likelihood methods implemented in PhyML under the LG $+\Gamma_{4}+\mathrm{I}$ model of evolution. Stars at nodes represent bootstrap $(\geq 70 \%)$ values. Scale bars indicate substitution per site. The new BSRV-like $C R-O 26$ strains are highlighted in red. RhPV was used as the out-group.

Finally, we compared the IRES sequences of BSRV, BSRV-like CR-026, AGV, WIV, AGLV, and RhPV in order to confirm their close relationship. Data indicates that they all presented a similar genetic structure with two identical bulges and stem loops (SL1 and SL2), as well as similar pseudo-knots (PK1, 2, 3) (Figure 5) [1].

The IGRs were grouped into two classes, I and II. The Cripavirus' IGRs belonged to the class I. The predicted base pairing was adapted from Jan et al. [1]. Bulges and stem loops are in bold. Stem loops predicted base pairing, and inverted repeat complementary sequences have been color-coded in red. Base pairing that formed pseudoknots PKI, PKII, and PKIII have been color-coded in green, blue, 
and orange, respectively. Conserved nucleotides have been replaced by dots, except for bulges and stem loops where letters are shown.

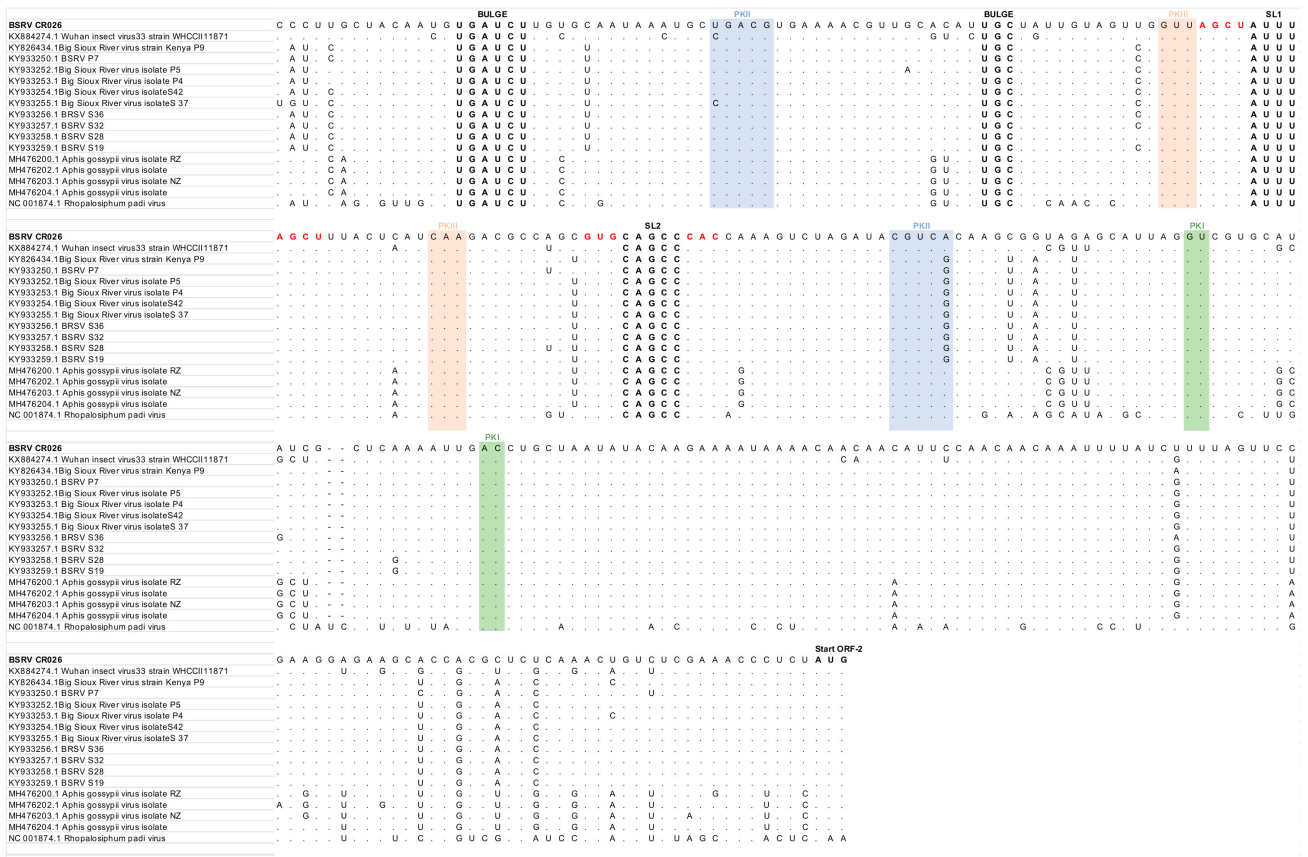

Figure 5. Comparison of class I IGRs of the Cripavirus genus.

\section{Discussion}

Although viruses belonging in the Dicistroviridae family have been described worldwide, only a few studies have been carried out in African mainland [12,23,29,30,45-47]. In this study, we described the full-length sequences of two Cripavirus (BSRV-like and ALPV) and one Aparavirus ( $A B P V$ ) obtained from the faeces of insectivorous bat species (Hipposideros caffer) collected in a cave dwelling in Zimbabwe.

Up to now, in African mainland, the ALPV full genome has been characterized only in South Africa and Kenya [12,48], whereas the full genome of the BSRV-like virus was first described in Kenya [12]. As for other dicistrovirus, very few data exist on $A B P V$ in Africa, and only three full genomes are available in GenBank —one from South Africa [49], and two from Poland and Hungary [50].

Dicistrovirus can cause dramatic damage to the agriculture sector. For example, numerous Dicistrovirus, likely combined with other factors, have been associated with honeybee colony losses (Collapse Disorder Colony (CDD)) [8]. The $A B P V$ is one such virus associated with this syndrome. In Zimbabwe, beekeeping is a growing farming activity. According to the Beekeepers Association of Zimbabwe, the country reached nearly 50,000 beekeepers who produced more than 1000 tons of honey per year (informal information). This activity represents a life-sustaining source of income and livelihood for small-scale farmers [51]. The characterization of ABPV in Zimbabwe's insectivorous bats suggested a broader circulation of this virus in the country and probably in the rest of southern Africa. Additional studies need to be carried out in Zimbabwe to assess the prevalence of $A B P V$ in beehives and to identify concomitant factors likely involved in CCD, such as Varroa's mite infections [8,52], considering that the presence of Dicistrovirus could be a major concern for the agricultural sector in future.

On one hand, some Dicistrovirus are studied for their use as potential bio-pesticides [3]. Aphids are key pests of many important crops worldwide [53], and the $A L P V$ is one of the recognized dicistroviruses which are pathogenic to insect pests of agricultural importance [3,54]. In Zimbabwe, agriculture, particularly tobacco farming, represents the most valuable economic agricultural income for the country, and the sector provides employment for up to 70 percent of the population. Chemical aphicides are preferentially used to control crop aphid invasion. The over- or misuse of chemical aphicide can led 
to aphid resistance, causing important yield losses [55]. Actually, bio-pesticides using lethal aphid viruses or natural predators could offer interesting alternatives to aphid proliferation control.

$B S R V$ s have been described in diverse arthropod hosts worldwide [12,18,21,22]. Nonetheless, their pathogenicity in hosts is yet to be clarified. The BSRV taxonomic classification by the ICTV, as many other dicistroviruses, is still pending [2]. From our results, BSRV-like CR-026 seemed to be a new Cripavirus based on the first part (ORF-1) of its genome, whereas the second part (ORF-2) of its genome suggests that it is close to the BSRVs previously characterized. Nonetheless, according to the ICTV, the species demarcation criteria within the Cripavirus is defined by the sequence identity at the amino-acid level between the capsid proteins of isolates and strains. Isolates with AA identities above $90 \%$ should be considered as the same species. Regarding this criterion, our new BSRV should be fully considered as a BSRV strain. However, considering the ORF-1 analyses, the taxonomic classification of BSRV-like CR026 remains difficult to establish. Besides the WIV and AGLV showed $100 \%$ of AA identities in both ORF-1 and ORF-2 (Capsid proteins) and have $91 \%$ of AA identities with the BSRV strains. Obviously, these two viruses, WIV and AGLV, are identical and belong to the BSRV strains (see Supplementary Materials, Table S6).

Recently, the Dicistrovirus has been reported in blood samples of human and bat species [29-31]. Although the identification of such viruses in humans was not clearly linked with their febrile state, these findings highlighted the potential spillover of such viruses in mammals and the need to identify its origin, particularly in the context of close contact between humans and bats, as observed in the current study site, and in all countries where bat guano is collected as fertilizer.

Finally, this study showed the potential of insectivorous bat faeces for the study of arthropod viromes. Insectivorous bats are generalized predators and they feed on a large number of insect species, following their availability as prey within the range of the insectivorous bat species [56,57]. As a colony of 300 insectivorous bats can consume around 2 to 6 million insects per year [57], insectivorous bats can be considered as a good collector of arthropod samples. Nonetheless, the Hipposideros caffer bat species is considered a moth specialist. Its diet consists predominantly of Lepidoptera [34,58,59]. In this study, we also checked the prey eaten by the $H$. caffer in our study site. Our result confirmed the previous reports with a majority of Lepidoptera found in the faeces, but also of dipters (see Supplementary Materials, Figure S2). The absence of Hymenoptera in our analysis suggested that the Dicistrovirus, such as the Acute Bee Paralysis Virus, can be hosted by other arthropods, and highlighted the need to further document the potential insect reservoirs of such viruses.

Supplementary Materials: The following are available online at http://www.mdpi.com/1999-4915/11/12/1102/s1, Figure S1: Phylogenetic analysis of partial bat $C y t B$ sequences $(550 \mathrm{bp})$, Figure S2: Order and family of insect found in the faeces' bats by NGS, Text S3: Command lines used for bioinformatic pre-analysis, Text S4: Specific primers used to fill the gap and to confirm the presence of Dicistrovirus in the feces samples, Text S5: Dicistrovirus reference strains used for the phylogenetic analyses presented in Figure 1, Table S6:Amino acid identities between $B S R V, A G V$, WIV and $A G L V$

Author Contributions: Conceived and designed the experiments: M.B., D.P., G.M., D.M., S.M., F.L. Performed the experiments: L.T., V.B., F.C., C.B., M.J., A.A., F.L. Analyzed the data: V.N., F.C., C.B., M.J., A.A., F.L. Contributed reagents/materials/analysis tools: F.C., C.B., P.B., D.M., M.J., A.A., F.L. Wrote the paper: M.B., D.P., G.M., D.M., S.M., F.L. Study conducted in the field: M.B., F.L.

Funding: This work was supported by grants of the Labex CeMEB (Recherche exploratoire, 1er edition), and the French Ministry of Europe and Foreign Affairs (Fond de Solidarité pour les Projets Innovants, les sociétés civiles, la francophonie et le développement humain-CAZCOM Project).

Acknowledgments: We thank Ngoni Chiweshe, Billy Butete and Cavin Mandina for their field assistance. We thank the Research Council of Zimbabwe for approving this study (research registration certificate $\mathrm{N}^{\circ} 03006$ ) and the Hurungwe Rural District council and the Zibagwe Rural District Council for their assistance and facilitation. We thank the Animal Research Ethics Committee of Zimbabwe for their approval (ref number 002/2017). Célia Barrachina acknowledges financial support from France Génomique National infrastructure, funded as part of "Investissement d'avenir" program managed by Agence Nationale pour la Recherche (contract ANR-10-INBS-09). This work was conducted within the framework of the Research Platform "Production and Conservation in Partnership" (RP-PCP).

Conflicts of Interest: We declare that we have no conflicts of interest. 


\section{References}

1. Jan, E. Divergent IRES elements in invertebrates. Virus Res. 2006, 119, 16-28. [CrossRef] [PubMed]

2. Valles, S.M.; Chen, Y.; Firth, A.E.; Guérin, D.M.A.; Hashimoto, Y.; Herrero, S.; de Miranda, J.R.; Ryabov, E. ICTV virus taxonomy profile: Dicistroviridae. J. Gen. Virol. 2017, 98, 355-356. [CrossRef] [PubMed]

3. Bonning, B.C.; Miller, W.A. Dicistroviruses. Annu. Rev. Entomol. 2010, 55, 129-150. [CrossRef] [PubMed]

4. Cox-Foster, D.L.; Conlan, S.; Holmes, E.C.; Palacios, G.; Evans, J.D.; Moran, N.A.; Quan, P.L.; Briese, T.; Hornig, M.; Geiser, D.M.; et al. A metagenomic survey of microbes in honey bee colony collapse disorder. Science 2007, 318, 283-287. [CrossRef] [PubMed]

5. Guo, Z.X.; He, J.G.; Xu, H.D.; Weng, S.P. Pathogenicity and complete genome sequence analysis of the mud crab dicistrovirus-1. Virus Res. 2013, 171, 8-14. [CrossRef]

6. Hasson, K.W.; Lightner, D.V.; Poulos, B.T.; Redman, R.M.; White, B.L.; Brock, J.A.; Bonami, J.R. Taura syndrome in Penaeus vannamei: Demonstration of a viral etiology. Dis. Aquat. Org. 1995, 23, 115-126. [CrossRef]

7. Pan, X.; Cao, Z.; Yuan, J.; Shi, Z.; Yuan, X.; Lin, L.; Xu, Y.; Yao, J.; Hao, G.; Shen, J. Isolation and characterization of a novel dicistrovirus associated with moralities of the great freshwater prawn, Macrobrachium rosenbergii. Int. J. Mol. Sci. 2016, 17, 204. [CrossRef]

8. Tantillo, G.; Bottaro, M.; Di Pinto, A.; Martella, V.; Di Pinto, P.; Terio, V. Virus infections of honeybees Apis Mellifera. Ital. J. Food Saf. 2015, 4, 5364. [CrossRef]

9. Culley, A.I.; Lang, A.S.; Suttla, C.A. Metagenomic analysis of coastal RNA virus communities. Science 2006, 312, 1795-1798. [CrossRef]

10. Victoria, J.G.; Kapoor, A.; Li, L.; Blinkova, O.; Slikas, B.; Wang, C.; Naeem, A.; Zaidi, S.; Delwart, E. Metagenomic analyses of viruses in stool samples from children with acute flaccid paralysis. J. Virol. 2009, 83, 4642-4651. [CrossRef]

11. Gomariz-Zilber, E.; Thomas-Orillard, M. Drosophila C virus and Drosophila hosts: A good association in various environments. J. Evol. Biol. 1993, 6, 677-689. [CrossRef]

12. Wamonje, F.O.; Michuki, G.N.; Braidwood, L.A.; Njuguna, J.N.; Musembi Mutuku, J.; Djikeng, A.; Harvey, J.J.W.; Carr, J.P. Viral metagenomics of aphids present in bean and maize plots on mixed-use farms in Kenya reveals the presence of three dicistroviruses including a novel Big Sioux River virus-like dicistrovirus. Virol. J. 2017, 14, 188. [CrossRef] [PubMed]

13. D'Arcy, C.J.; Burnett, P.A.; Hewings, A.D. Detection, biological effects, and transmission of a virus of the aphid Rhopalosiphum padi. Virology 1981, 114, 268-272. [CrossRef]

14. Hatfill, S.J.; Williamson, C.; Kirby, R.; von Wechmar, M.B. Identification and localization of aphid lethal paralysis virus particles in thin tissue sections of the Rhopalosiphum padi aphid by in situ nucleic acid hybridization. J. Invertebr. Pathol. 1990, 55, 265-271. [CrossRef]

15. Reinganum, C.; O'Loughlin, G.T.; Hogan, T.W. A nonoccluded virus of the field crickets Teleogryllus oceanicus and T. commodus (Orthoptera: Gryllidae). J. Invertebr. Pathol. 1970, 16, 214-220. [CrossRef]

16. Remnant, E.J.; Mather, N.; Gillard, T.L.; Yagound, B.; Beekman, M. Direct transmission by injection affects competition among RNA viruses in honeybees. Proc. R. Soc. B Biol. Sci. 2019, 286. [CrossRef]

17. Carissimo, G.; Eiglmeier, K.; Reveillaud, J.; Holm, I.; Diallo, M.; Diallo, D.; Vantaux, A.; Kim, S.; Ménard, D.; Siv, S.; et al. Identification and characterization of two novel RNA viruses from Anopheles gambiae species complex mosquitoes. PLoS ONE 2016, 11, e0153881. [CrossRef]

18. Feng, Y.; Krueger, E.N.; Liu, S.; Dorman, K.; Bonning, B.C.; Miller, W.A. Discovery of known and novel viral genomes in soybean aphid by deep sequencing. Phytobiomes J. 2017, 1, 36-45. [CrossRef]

19. Nakasu, E.Y.T.; Hedil, M.; Nagata, T.; Michereff-Filho, M.; Lucena, V.S.; Inoue-Nagata, A.K. Complete genome sequence and phylogenetic analysis of a novel dicistrovirus associated with the whitefly Bemisia tabaci. Virus Res. 2019, 260, 49-52. [CrossRef]

20. Roberts, J.M.K.; Anderson, D.L.; Durr, P.A. Metagenomic analysis of Varroa-free Australian honey bees (Apis mellifera) shows a diverse Picornavirales virome. J. Gen. Virol. 2018, 99, 818-826. [CrossRef]

21. Runckel, C.; Flenniken, M.L.; Engel, J.C.; Ruby, J.G.; Ganem, D.; Andino, R.; DeRisi, J.L. Temporal analysis of the honey bee microbiome reveals four novel viruses and seasonal prevalence of known viruses, Nosema, and Crithidia. PLoS ONE 2011, 6, e20656. [CrossRef] [PubMed] 
22. Shi, C.; Liu, Y.; Hu, X.; Xiong, J.; Zhang, B.; Yuan, Z. A metagenomic survey of viral abundance and diversity in mosquitoes from hubei province. PLOS ONE 2015, 10, e0129845. [CrossRef] [PubMed]

23. Duraisamy, R.; Akiana, J.; Davoust, B.; Mediannikov, O.; Michelle, C.; Robert, C.; Parra, H.J.; Raoult, D.; Biagini, P.; Desnues, C. Detection of novel RNA viruses from free-living gorillas, Republic of the Congo: Genetic diversity of picobirnaviruses. Virus Genes 2018, 54, 256-271. [CrossRef] [PubMed]

24. Ge, X.; Li, Y.; Yang, X.; Zhang, H.; Zhou, P.; Zhang, Y.; Shi, Z. Metagenomic analysis of viruses from bat fecal samples reveals many novel viruses in insectivorous bats in China. J. Virol. 2012, 86, 4620-4630. [CrossRef]

25. Krumbholz, A.; Groth, M.; Esefeld, J.; Peter, H.-U.; Zelld, R. Genome sequence of a novel picorna- like RNA virus from feces of the antarctic fur seal (Arctocephalus gazella). Genome Annouc. 2017, 5, 17-18. [CrossRef]

26. Reuter, G.; Pankovics, P.; Gyöngyi, Z.; Delwart, E.; Boros, Á. Novel dicistrovirus from bat guano. Arch. Virol. 2014, 159, 3453-3456. [CrossRef]

27. Li, L.; Victoria, J.G.; Wang, C.; Jones, M.; Fellers, G.M.; Kunz, T.H.; Delwart, E. Bat guano virome: Predominance of dietary viruses from insects and plants plus novel mammalian viruses. J. Virol. 2010, 84, 6955-6965. [CrossRef]

28. Zhang, W.; Yang, S.; Shan, T.; Hou, R.; Liu, Z.; Li, W.; Guo, L.; Wang, Y.; Chen, P.; Wang, X.; et al. Virome comparisons in wild-diseased and healthy captive giant pandas. Microbiome 2017, 5, 90. [CrossRef]

29. Bennett, A.J.; Bushmaker, T.; Cameron, K.; Ondzie, A.; Niama, F.R.; Parra, H.-J.; Mombouli, J.-V.; Olson, S.H.; Munster, V.J.; Goldberg, T.L. Diverse RNA viruses of arthropod origin in the blood of fruit bats suggest a link between bat and arthropod viromes. Virology 2019, 528, 64-72. [CrossRef]

30. Cordey, S.; Laubscher, F.; Hartley, M.-A.; Junier, T.; Pérez-Rodriguez, F.J.; Keitel, K.; Vieille, G.; Samaka, J.; Mlaganile, T.; Kagoro, F.; et al. Detection of dicistroviruses RNA in blood of febrile Tanzanian children. Emerg. Microbes Infect. 2019, 8, 613-623. [CrossRef]

31. Phan, T.G.; Del Valle Mendoza, J.; Sadeghi, M.; Altan, E.; Deng, X.; Delwart, E. Sera of Peruvians with fever of unknown origins include viral nucleic acids from non-vertebrate hosts. Virus Genes 2015, 20, 163-178. [CrossRef] [PubMed]

32. Bourgarel, M.; Pfukenyi, D.M.; Boué, V.; Talignani, L.; Chiweshe, N.; Diop, F.; Caron, A.; Matope, G.; Missé, D.; Liégeois, F. Circulation of Alphacoronavirus, Betacoronavirus and Paramyxovirus in Hipposideros bat species in Zimbabwe. Infect. Genet. Evol. 2018, 58, 253-257. [CrossRef] [PubMed]

33. Kocher, T.D.; Thomas, W.K.; Meyer, A.; Edwards, S.V.; Paabo, S.; Villablanca, F.X.; Wilson, A.C. Dynamics of mitochondrial DNA evolution in animals: Amplification and sequencing with conserved primers (cytochrome b/12S ribosomal DNA/control region/evolutionary genetics/molecular phylogenies). Evolution (N. Y.) 1989, $86,6196-6200$.

34. Monadjem, A.; Taylor, P.J.; Cotterill, F.P.D.; Schoeman, M.C. Bats of Southern and Central Africa: A Biogeographic and Taxonomic Synthesis; Wits University Press: Johannesburg, South Africa, 2010; ISBN 978-1-86814-508-9.

35. Gillet, F.; Tiouchichine, M.-L.; Galan, M.; Blanc, F.; Némoz, M.; Aulagnier, S.; Michaux, J.R. A new method to identify the endangered Pyrenean desman (Galemys pyrenaicus) and to study its diet, using next generation sequencing from faeces. Mamm. Biol. 2015, 80, 505-509. [CrossRef]

36. Andriollo, T.; Gillet, F.; Michaux, J.R.; Ruedi, M. The menu varies with metabarcoding practices: A case study with the bat Plecotus auritus. PLoS ONE 2019, 14, e0219135. [CrossRef]

37. Goodacre, N.; Aljanahi, A.; Nandakumar, S.; Mikailov, M.; Khan, A.S. A Reference Viral Database (RVDB) to enhane bioinformatics analysis of high-throughput sequencing for novel virus detection. mSphere 2018, 3, e00069-18. [CrossRef]

38. Camacho, C.; Coulouris, G.; Avagyan, V.; Ma, N.; Papadopoulos, J.; Bealer, K.; Madden, T.L. BLAST+: Architecture and applications. BMC Bioinform. 2009, 10, 421. [CrossRef]

39. Kumar, S.; Stecher, G.; Tamura, K. MEGA7: Molecular evolutionary genetics analysis version 7.0 for bigger datasets. Mol. Biol. Evol. 2016, 33, 1870-1874. [CrossRef]

40. Guindon, S.; Dufayard, J.F.; Lefort, V.; Anisimova, M.; Hordijk, W.; Gascuel, O. New algorithms and methods to estimate maximum-likelihood phylogenies: Assessing the performance of PhyML 3.0. Syst. Biol. 2010, 59, 307-321. [CrossRef]

41. Milne, I.; Lindner, D.; Bayer, M.; Husmeier, D.; Mcguire, G.; Marshall, D.F.; Wright, F. TOPALi v2: A rich graphical interface for evolutionary analyses of multiple alignments on HPC clusters and multi-core desktops. Bioinformatics 2009, 25, 126-127. [CrossRef] 
42. Larkin, M.A.; Blackshields, G.; Brown, N.P.; Chenna, R.; Mcgettigan, P.A.; McWilliam, H.; Valentin, F.; Wallace, I.M.; Wilm, A.; Lopez, R.; et al. Clustal W and Clustal X version 2.0. Bioinformatics 2007, 23, 2947-2948. [CrossRef] [PubMed]

43. Ratnasingham, S.; Hebert, P.D.N. BOLD: The barcode of life data system (www.barcodinglife.org). Mol. Ecol. Notes 2007, 7, 355-364. [CrossRef] [PubMed]

44. Valles, S.M.; Rivers, A.R. Nine new RNA viruses associated with the fire ant Solenopsis invicta from its native range. Virus Genes 2019, 55, 368-380. [CrossRef] [PubMed]

45. Haddad, N.; Horth, L.; Al-Shagour, B.; Adjlane, N.; Loucif-Ayad, W. Next-generation sequence data demonstrate several pathogenic bee viruses in Middle East and African honey bee subspecies (Apis mellifera syriaca, Apis mellifera intermissa) as well as their cohabiting pathogenic mites (Varroa destructor). Virus Genes 2018, 54, 694-705. [CrossRef] [PubMed]

46. Kajobe, R.; Marris, G.; Budge, G.; Laurenson, L.; Cordoni, G.; Jones, B.; Wilkins, S.; Cuthbertson, A.G.S.; Brown, M.A. First molecular detection of a viral pathogen in Ugandan honey bees. J. Invertebr. Pathol. 2010, 104, 153-156. [CrossRef]

47. Benjeddou, M.; Leat, N.; Allsopp, M.; Davison, S. Detection of acute bee paralysis virus and black queen cell virus from honeybees by reverse transcriptase PCR. Appl. Environ. Microbiol. 2001, 67, 2384-2387. [CrossRef]

48. Van Munster, M.; Dullemans, A.M.; Verbeek, M.; Van Den Heuvel, J.F.; Clérivet, A.; Van Der Wilk, F. Sequence analysis and genomic organization of Aphid lethal paralysis virus: A new member of the family Dicistroviridae. J. Gen. Virol. 2002, 83 Pt 12, 3131-3138. [CrossRef]

49. Govan, V.A.; Leat, N.; Allsopp, M.; Davison, S. Analysis of the complete genome sequence of acute bee paralysis virus shows that it belongs to the novel group of insect-infecting RNA viruses. Virology 2000, 277, 457-463. [CrossRef]

50. Bakonyi, T.; Grabensteiner, E.; Kolodziejek, J.; Rusvai, M.; Topolska, G.; Ritter, W.; Nowotny, N. Phylogenetic analysis of acute bee paralysis virus strains. Appl. Environ. Microbiol. 2002, 68, 6446-6450. [CrossRef]

51. Hilmi, M.; Bradbear, N.; Mejia, D. Beekeeping and Sustainable Livelihoods; Rural Infrastructure and Agro-Industries Division Food and Agriculture Organization of the United Nations: Rome, Italy, 2011; ISBN 9789251070628.

52. McMenamin, A.J.; Flenniken, M.L. Recently identified bee viruses and their impact on bee pollinators. Curr. Opin. Insect Sci. 2018, 26, 120-129. [CrossRef]

53. Van Emdem, H.F.; Harrington, R. (Eds.) Aphids as Crop Pests, 2nd ed.; CABI: Wallingfor, UK, 2017; ISBN 9788578110796.

54. Williamson, C.; Rybicki, E.P.; Kasdorf, G.G.F.; Von Wechmar, M.B. Characterization of a new picorna-like virus isolated from Aphids. J. Gen. Virol. 1988, 69, 787-795. [CrossRef]

55. Rhoda, M.; Upenyu, M.; Peter, C.; Susan, D. The response of the red morph of the Tobacco aphid, myzus persicae nicotianae, to insecticides applied under laboratory and field conditions. Asian J. Agric. Rural Dev. 2013, 3, 141-147.

56. Belwood, J.J.; Fenton, M.B. Variation in the diet of Myotis lucifiugus (Chiroptera: Vespertilionidae). Can. J. Zool. 1976, 54, 1674-1678. [CrossRef]

57. Barclay, R.M.R.; Brigham, R.M. Constraints on optimal foraging: A field test ofprey discrimination by echolocating insectivorous bats. Anim. Behav. 1994, 48, 1013-1021. [CrossRef]

58. Whitaker, J.O.; Clem, P. Food of the evening bat Nycticeius humeralis from Indiana. Am. Midl. Nat. 1992, 127, 211-217. [CrossRef]

59. Spanjer-Wright, G. Hipposideros caffer (Chiroptera: Hipposideridae). Mamm. Species 2009, 845, 1-9. [CrossRef]

(C) 2019 by the authors. Licensee MDPI, Basel, Switzerland. This article is an open access article distributed under the terms and conditions of the Creative Commons Attribution (CC BY) license (http://creativecommons.org/licenses/by/4.0/). 